(C) Inra/Elsevier, Paris

Original article

\title{
Genetic variation in Spanish populations of the genus Aegilops revealed by RAPDs
}

\author{
Juan-Vicente Monte, Carlos Casanova, Consuelo Soler ${ }^{*}$ \\ Department of Plant Breeding and Biotechnology, C.I.T., I.N.I.A., La Canaleja, P.O. Box 1100 , \\ 28008, Alcala de Henares, Madrid, Spain
}

(Received 26 January 1999, accepted 16 April 1999)

\begin{abstract}
Random amplified polymorphic DNA (RAPD) markers were used to analyse genetic variability and relationships in wild species of the genus Aegilops. Fifty natural populations, which included the species Aegilops biuncialis (UUMM), Ae. neglecta (UUMMNN), Ae. ovata (UUMM), Ae. ventricosa (DDNN) and Ae. triuncialis (UUCC) were selected. These populations are widely distributed in the Iberian peninsula and Balearic islands. Twenty primers were used to generate DNA amplification data. Genetic relationships were established by correspondence analysis. In the resulting dendrogram, Ae. ventricosa appears to be segregated from the other species, probably owing to the influence of the D genome. Ae. biuncialis and Ae. ovata are clearly separated suggesting that the superindex system should be used to differentiate the $M$ genomes of both species. The separation of the $M$ and $N$ genomes was also confirmed, as was the proximity of $\mathrm{N}$ to $\mathrm{U}$ and $\mathrm{C}$ to $\mathrm{M}$. In addition, correlation was found between RAPD markers and ecogeographical factors. (@ Inra/Elsevier, Paris.)
\end{abstract}

Aegilops / RAPDs / genetic diversity / ecogeographical factors

Resumé - Variation génétique dans des populations espagnoles du genre Aegilops étudiées par RAPD. Les marqueurs RAPD (ADN polymorphe amplifié aléatoirement) ont été utilisés dans une étude des relations génétiques entre les espèces du genre Aegilops. On a sélectionné cinquante populations naturelles des espèces de Aegilops biuncialis, Ae. neglecta, Ae. ovata, Ae. ventricosa, et Ae. triuncialis. Ces populations ont une ample répartition sur la Péninsule Ibérique et les Îles Baléares. Vingt oligonucléotides ont été choisis pour obtenir les données de l'ADN amplifié. Les relations génétiques ont été estimées à l'aide des techniques d'analyse de correspondance. Dans le dendrogramme résultant Ae. ventricosa apparaît éloigné des autres espèces, peut être à cause de l'influence de génome $\mathrm{D}$. La séparation nette de Ae. biuncialis et Ae. ovata permet de penser que le système de superindex devrait être utilisé pour différencier les génomes $M$ de deux espèces. On confirme aussi la séparation de génomes $M$ et $N$, ainsi que la proximité des génomes $\mathrm{N}$ et $\mathrm{U}$ et $\mathrm{C}$ et $\mathrm{M}$. De plus des corrélations entre les marqueurs RAPD et des facteurs ecogéographiques ont été observées. (C) Inra/Elsevier, Paris.)

Aegilops / RAPDs / diversité génétique / facteurs écogéographiques

Communicated by Nicolás Jouve (Alcalá de Henares, Madrid, Spain)

* Correspondence and reprints

llinares@inia.es 


\section{Introduction}

Cereal breeders refer to the species of the genus Aegilops as the wild relatives of wheat. They probably represent the main genetic reserve available for the improvement of the wheat cultivar $[4,14]$. Aegilops species are mostly annual and autogamous. Polyploid forms exist, arising by evolutionary convergence of ancestral diploid species [27]. The distribution of the genus Aegilops extends from southwest and central Asia to the Mediterranean basin with Turkey as the centre of diversification. The genus has adapted in such a way that all the species are annual and survive the extreme Mediterranean summers as seeds. Spain is especially rich in wild populations of the polyploid species Aegilops biuncialis Vis. (UUMM), Ae. triuncialis L. (UUCC), Ae. ovata L. (UUMM) and Ae. ventricosa Tausch (DDNN), all of which are allotetraploids, and Ae. neglecta Req. ex Bert. (UUMM/UUMMNN) which is found naturally in both tetraploid and hexaploid forms [9, 14, 26]. The hexaploid variant (Ae. neglecta subsp. recta Zhuck and Hammer) was selected for the present study since the tetraploid is not found in the Iberian peninsula. Aegilops ovata and Ae. triuncialis are widely distributed in Spain except in the north and northwest, areas which are typified by cool, damp summers. Aegilops neglecta, Ae. biuncialis and Ae. ventricosa may be found in more restricted areas [20]. Aegilops caudata L (CC), Ae. commosa Sibth. and Sm (MM), Ae. uniaristata Vis. (NN), Ae. umbellulata Zhuck (UU) and $A e$. squarrosa Coss. (DD) are the proposed diploid ancestors of the species mentioned above and were used as phylogenetic markers.

Over several years, the present authors have explored the Iberian peninsula and collected wild populations of Aegilops with the aim of introducing native material into plant breeding programmes, mainly those involving wheat and Triticale. Special care must be taken to preserve the original structure of the natural populations. The collection method of Hawkes [10] increases the genetic value of the material harvested. Indeed, if the genetic individuality of a plant is maintained, genes of interest may be detected in individual plants, and their allelic frequencies calculated for each population. This is an important consideration in the selection of a plant breeding strategy.

Studies of genetic variability in natural populations are extremely useful during the process of introducing wild material into plant breeding programmes. Besides, although in the past many useful cytological and biochemical studies have examined the genetic relationships within the genus [2, $12,18,19]$, the information available is far from complete and further molecular data are required if valid taxonomic conclusions are to be drawn. The aim of the present work was to study the interpopulational variability in different Aegilops species and their interspecific genomic relationships.

RAPD markers are extensively used in the evaluation of variability and genetic relationships despite some limitations mainly concerning the lack of reproducibility in different laboratories. This screening method, based on DNA sequence polymorphisms in primer binding regions, is easy to perform, fast, inexpensive and efficient $[3,5,7$, $17,22,23,25,28,29]$.

\section{Materials and methods}

\subsection{Plant material}

Fifty populations of five Aegilops species growing in Spain and samples of five diploid species regarded as the ancestral donors of these tetraploid forms were used. Ten populations per species of Ae. biuncialis, Ae. triuncialis, Ae ovata, Ae ventricosa and Ae. neglecta were selected for the study. This plant material belongs to the living collection of wild Triticeae collected from natural environments, maintained at the I.N.I.A. plant breeding unit (La Canaleja, Madrid, Spain). Specimens were collected according to the method of Hawkes [10]. These populations are representatives of the total geographical distribution of the five species in Spain [20]. The species found in Spain, populations and their geographical origin are shown in figure 1. Single populations of Ae caudata, Ae commosa, Ae uniaristata, Ae umbellulata and Ae. squarrosa provided by the Royal Botanical Gardens of London (UK) were also included in the study. 


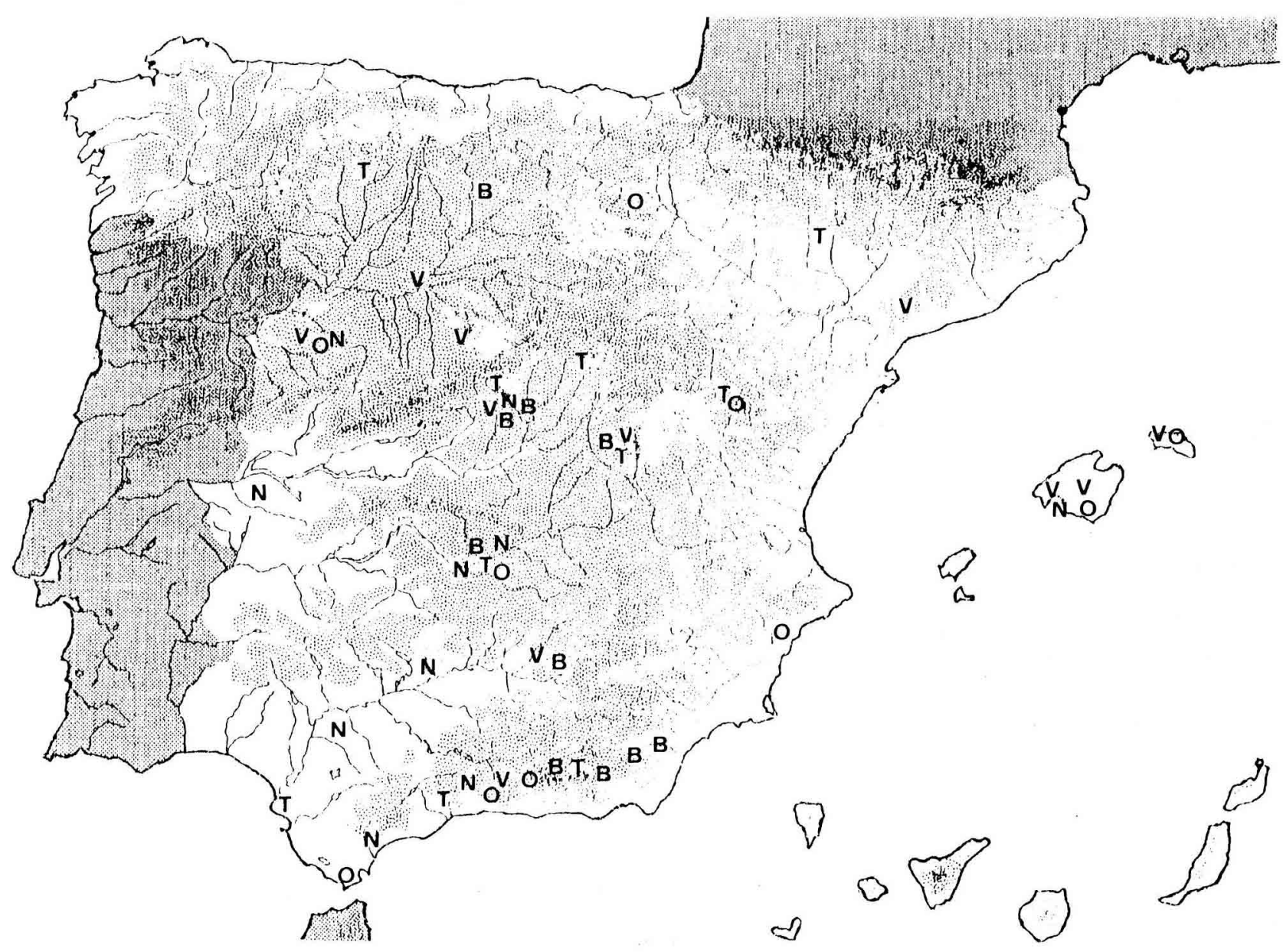

Figure 1. Geographical distribution of the Spanish Aegilops species and populations used in the study: Ae. ventricosa (V), Ae. ovata (O), Ae. triuncialis (T), Ae. biuncialis $(\mathrm{B})$ and Ae. neglecta $(\mathrm{N})$.

\subsection{Genome extraction and PCR procedures}

Genomic DNA was extracted from young, green leaves of 20-30 individual specimens of each population, according to the method of Dellaporta et al. [6]. PCR amplification was performed in a $25 \mu \mathrm{L}$ reaction volume containing $7.5 \mathrm{ng}$ primer, $12.5 \mathrm{ng}$ DNA, $2.5 \mu \mathrm{L}$ reaction buffer $10 \times, 100 \mathrm{mM}$ dNTPs and 1.25 units of Taq DNA polymerase (Bioprobe). Eighty 10-mer random primers used were provided by $M, R, S$ and $T$ kits (Operon technologies). A further ten primers were synthesised. Amplifications were made in a PTC-100 MJ Research Inc. thermocycler as follows: 41 cycles of 1 min at $94{ }^{\circ} \mathrm{C}, 1 \mathrm{~min}$ at $36^{\circ} \mathrm{C}, 2 \mathrm{~min}$ at $72{ }^{\circ} \mathrm{C}$, and $5 \mathrm{~min}$ at $72{ }^{\circ} \mathrm{C}$ [28]. The amplification products were separated by electrophoresis in $1.8 \%$ agarose gel using TAE buffer and visualised by ethidium bromide staining. Boeringer Manheim marker VI (174-2 176) was used as the molecular marker.

\subsection{Statistical analyses}

RAPD data were scored in a global matrix. Amplified bands of identical size were considered to be the same marker and the presence (1) or absence (0) of bands were considered as character states. The data matrix was analysed with the NTSYS computer package (version 1.50) [21]. Correspondence analysis [17] and 


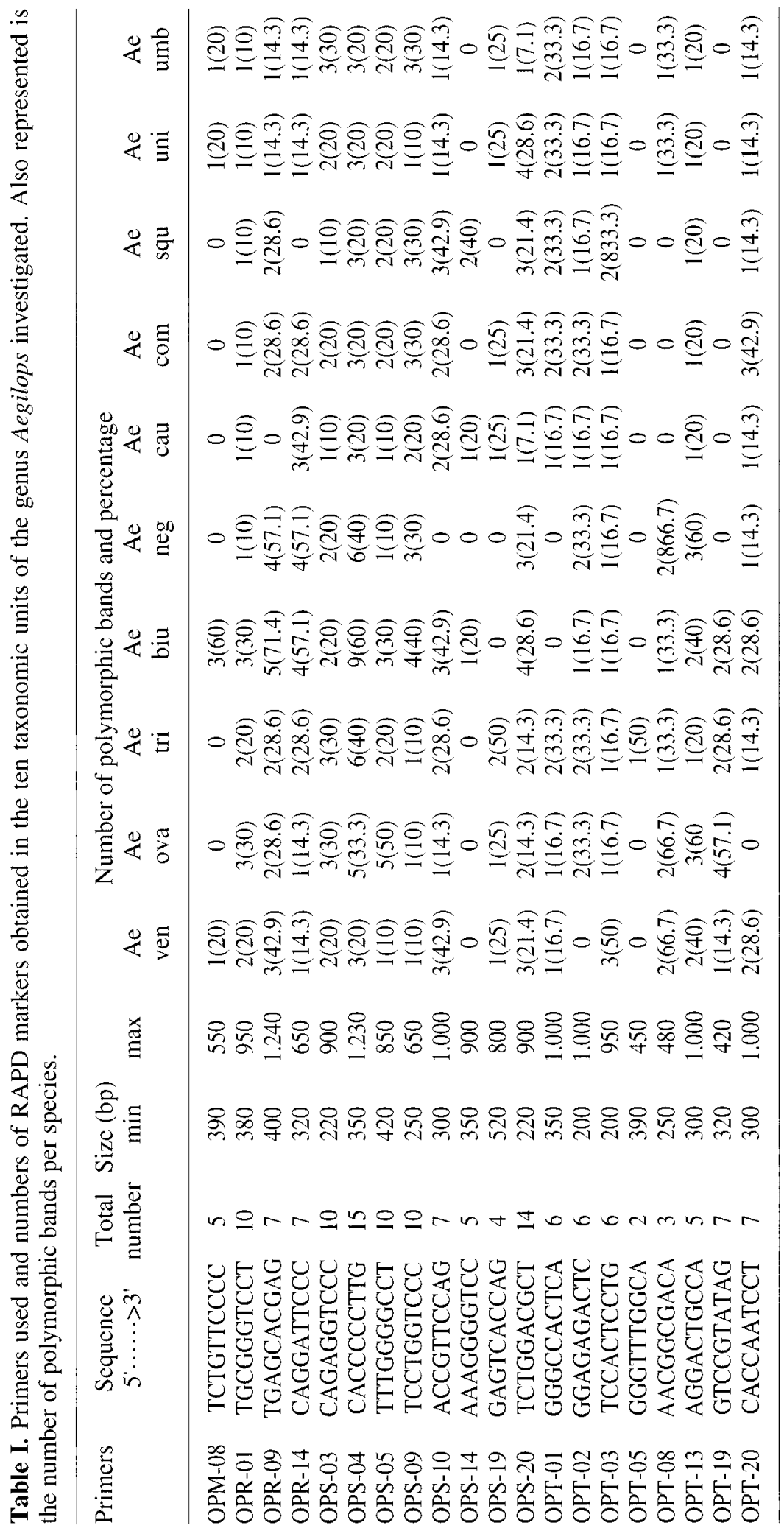


Table II. Number of RAPD products generated (diagonal) and shared (remaining data) by 20 primers in ten Aegilops species. The number of specific markers found in each taxonomic unit is indicated in brackets.

\begin{tabular}{|c|c|c|c|c|c|c|c|c|c|c|}
\hline & $\begin{array}{l}\mathrm{Ae} \\
\text { ven }\end{array}$ & $\begin{array}{l}\text { Ae } \\
\text { ova }\end{array}$ & $\begin{array}{l}\mathrm{Ae} \\
\text { tri }\end{array}$ & $\begin{array}{l}\mathrm{Ae} \\
\text { biu }\end{array}$ & $\begin{array}{l}\mathrm{Ae} \\
\text { neg }\end{array}$ & $\begin{array}{l}\mathrm{Ae} \\
\mathrm{cau}\end{array}$ & $\begin{array}{c}\mathrm{Ae} \\
\text { com }\end{array}$ & $\begin{array}{l}\mathrm{Ae} \\
\text { squ }\end{array}$ & $\begin{array}{l}\mathrm{Ae} \\
\text { uni }\end{array}$ & $\begin{array}{c}\mathrm{Ae} \\
\text { umb }\end{array}$ \\
\hline Ae. ventricosa & $47(9)$ & $26(0)$ & $23(0)$ & $26(0)$ & $26(1)$ & $20(0)$ & $21(1)$ & $28(7)$ & $23(0)$ & $22(0)$ \\
\hline Ae. ovata & & $51(7)$ & $34(1)$ & $38(3)$ & $32(1)$ & $22(0)$ & $21(1)$ & $16(0)$ & $29(0)$ & $33(2)$ \\
\hline Ae. triuncialis & & & 51 & 36 & 31 & 27 & 29 & 21 & 30 & 32 \\
\hline Ae. biuncialis & & & & $69(14)$ & $40(2)$ & $25(0)$ & $32(1)$ & $23(0)$ & $35(0)$ & $35(0)$ \\
\hline Ae. neglecta & & & & & $54(8)$ & $21(1)$ & $26(0)$ & $20(0)$ & $29(0)$ & $30(0)$ \\
\hline Ae caudata & & & & & & $35(4)$ & $27(2)$ & $12(1)$ & $25(0)$ & $23(0)$ \\
\hline Ae. comosum & & & & & & & $49(6)$ & $22(0)$ & $28(0)$ & $28(1)$ \\
\hline Ae. squarrosa & & & & & & & & $42(10)$ & $23(0)$ & $21(0)$ \\
\hline Ae. uniaristata & & & & & & & & & $39(0)$ & $33(0)$ \\
\hline Ae. umbellulata & & & & & & & & & & $42(3)$ \\
\hline
\end{tabular}

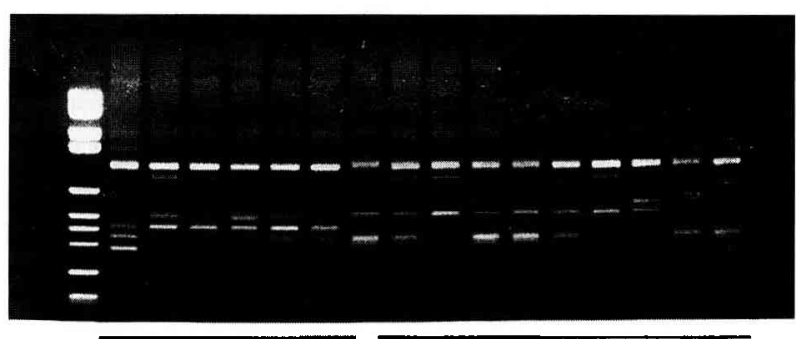

Ae. ovata

Ae. triuncialis

Figure 2. Intra- and interspecific polymorphisms revealed by amplification with primer Rl in six populations of Ae. ovata and ten Ae. triuncialis.

the unweighted pair group method (UPGMA) [24] were used to construct a dendrogram. Correlations between RAPD markers and ecogeographical variables were determined by the Spearman rank order correlation coefficient, using SPSS software (SPSS Inc., 1989-1995, version 6.1.3).

\section{Results and discussion}

\subsection{Interpopulational and interspecific analyses}

Of the 90 arbitrary 10 -mer primers tested, 20 produced adequate DNA amplification patterns in each species. Bias based polymorphisms were carefully avoided [3]. RAPD amplifications were performed in triplicate and only reproducible bands were scored (figure 2). A total of 146 RAPD products were recorded of which $131(89.7 \%)$ detected polymorphisms. Fifty-six showed variability at the interpopulational level, and 75 could discriminate only at the species level. The number of amplified bands per primers ranged from 15 (S-4) to 2 (T-5). Fragment size ranged from 200 to $1240 \mathrm{bp}$ (table I). Ae. biuncialis showed the highest degree of variation with $43.7 \%$ polymorphic bands between populations. Ae. neglecta showed the least variation $(7.5 \%)$. The remaining values were $21.6 \%$ (Ae. ovata), $21.6 \%$ (Ae. triuncialis) and $10.5 \%$ (Ae. ventricosa). Only nine bands were specific to single populations $(6.2 \%)$ while 68 $(46.6 \%)$ were present only in single species as described in table II.

The dendrogram generated (figure 3) was of sufficient resolution to clearly separate all the species and most populations. However, several populations of Ae. neglecta, Ae. ventricosa and Ae. triuncialis were not resolved. The low level of intraspecific variation detected in Ae. ventricosa and Ae. neglecta (table III) is consistent with the tendency of these species to colonise similar ecological habitats in different geographical locations of the Iberian peninsula [20].

Ae. ventricosa was associated with Ae. squarrosa (DD) and was clearly segregated from the other species. This is probably due to the influence 


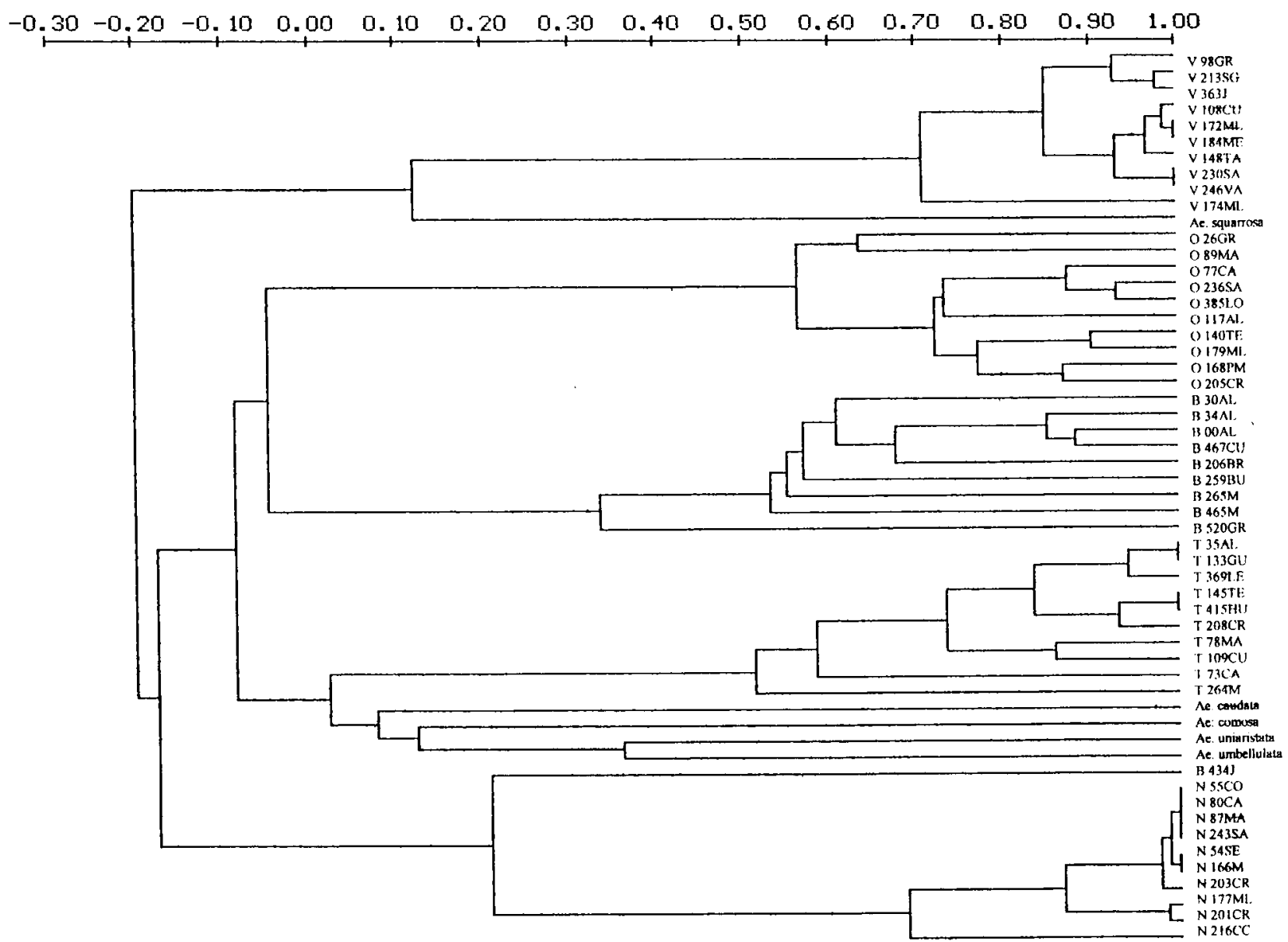

Figure 3. Dendrogram of the Aegilops species and populations used generated by NTSYS and UPGMA. The Pearson correlation coefficient was used to estimate genetic distances.

Table III. Mean, coefficients of variation and variance for each Aegilops species according to similarity indices between populations.

\begin{tabular}{lccc}
\hline & Mean & Variance & Coef. of Variation \\
\hline Ae. ventricosa & 0.875206 & 0.010062 & $11.46 \%$ \\
Ae. ovata & 0.717279 & 0.023189 & $21.23 \%$ \\
Ae. triuncialis & 0.742287 & 0.031991 & $24.10 \%$ \\
Ae. biuncialis & 0.506344 & 0.076132 & $54.49 \%$ \\
Ae. neglecta & 0.900663 & 0.013363 & $12.83 \%$ \\
\hline
\end{tabular}

of the $\mathrm{D}$ genome. This genome has undergone less change than other diploid genomes during evolu- tion and therefore appears to be less modified and is well separated within the Triticeae [1, 4]. Ae. biuncialis, Ae. ovata and Ae.triuncialis, the tetraploid species which share the U genome, cluster together owing probably to the influence of this genome. However, Ae. neglecta, another species of the U group, although shown to be related to these species, was relatively distant. Given that $A e$. neglecta is hexaploid, the tree seems to reflect differences at the ploidy level. All the diploid species, except Ae. squarrosa, were closely associated with Ae. triuncialis. The $\mathrm{U}$ and $\mathrm{C}$ genomes of Ae. triuncialis have undergone almost no evolutionary change with respect to the same genomes in other 
Table IV. Significant correlations $(P=0.01)$ between ecogeographical variables and RAPD markers. The sign of the correlation $(+/-)$ is indicated after the species containing the marker $(\mathrm{V}=$ Ae. ventricosa, $\mathrm{T}=$ Ae. triuncialis, $\mathrm{O}=A e$. ovata, $\mathrm{B}=$ Ae. biuncialis, $\mathrm{N}=$ Ae. neglecta). The markers are indicated with the primer used followed by a code number. The ecogeographical variables evaluated were: soil, Tanu (mean annual temperature), Tmin (mean minimum temperature of the coldest month), Panu (mean annual rainfall), Pver (summer rainfall), Alt (altitude), Lat (latitude), Lon (longitude), TI (thermal index $=\mathrm{Tanu}+\mathrm{Tmin}+\mathrm{T} \max$ (mean maximum temperature of the coldest month), MI (Mediterranean factor index = evapo-transpiration potential in June, July and August/mean rainfall for the same period), FFD (frost-free day index $=$ number of days per year with temperatures above $0{ }^{\circ} \mathrm{C}$ ).

\begin{tabular}{|c|c|c|c|c|c|c|c|c|c|c|c|}
\hline & Soil & Tanu & Tmin & Panu & Pver & Alt & Lat & Lon & TI & MI & FFD \\
\hline T20-1 & --- & --- & --- & --- & --- & --- & --- & $\mathrm{T}^{+} \mathrm{B}^{+} \mathrm{N}^{+}$ & --- & --- & --- \\
\hline T20-2 & --- & $\mathrm{V}^{-}$ & --- & --- & --- & --- & --- & --- & --- & --- & --- \\
\hline S14-1 & --- & -.. & --- & --- & --- & $\mathrm{B}^{+}$ & -- & --- & --- & --- & --- \\
\hline S09-1 & --- & --- & --- & $\mathrm{B}^{+} \mathrm{N}^{+}$ & --- & --- & --- & --- & --- & --- & --- \\
\hline S09-2 & --- & --- & --- & $\mathrm{B}^{+} \mathrm{N}^{+}$ & --- & --- & $\ldots$ & --- & --- & --- & --- \\
\hline S09-3 & --- & --- & --- & $\mathrm{B}^{+} \mathrm{N}^{+}$ & --- & --- & --- & --- & --- & --- & --- \\
\hline S09-4 & --- & --- & --- & --- & -- & --- & --- & --- & --- & $\mathrm{O}^{+} \mathrm{B}^{+} \mathrm{N}^{+}$ & --- \\
\hline T08-1 & --- & --- & --- & --- & --- & $\mathrm{V}^{-} \mathrm{O}^{-} \mathrm{N}^{-}$ & --- & --- & --- & --- & --- \\
\hline T13-1 & --- & -- & --- & $\mathrm{N}^{+}$ & --- & --- & --- & -- & --- & --- & --- \\
\hline R09-1 & $\ldots$ & $\mathrm{O}^{+} \mathrm{B}^{+} \mathrm{N}^{+}$ & --- & --- & --- & --- & --- & --- & --- & --- & --- \\
\hline R09-2 & --- & --- & --- & --- & --- & --- & $\mathrm{B}^{+}$ & --- & --- & --- & --- \\
\hline S20-1 & --- & --- & $\cdots$ & $\mathrm{B}^{+} \mathrm{N}^{+}$ & --- & -- & --- & --- & --- & --- & --- \\
\hline S20-2 & --- & --- & --- & $\mathrm{B}^{+} \mathrm{N}^{+}$ & -- & --- & -- & --- & --- & --- & --- \\
\hline $\mathrm{S} 20-3$ & --- & --- & --- & --- & $\mathrm{N}^{+}$ & --- & --- & -.- & --- & --- & --- \\
\hline T02-1 & --- & --- & --- & $\mathrm{O}^{+} \mathrm{N}^{+}$ & --- & $\mathrm{O}^{-} \mathrm{N}^{-}$ & --- & --- & -- & --- & --- \\
\hline R01-1 & --- & --- & --- & --- & --- & $\mathrm{B}^{+}$ & --- & --- & --- & --- & --- \\
\hline R01-2 & --- & -- & --- & $\mathrm{B}^{+} \mathrm{N}^{+}$ & --- & --- & --- & -- & --- & -- & --- \\
\hline R01-3 & --- & --- & --- & $\mathrm{N}^{+}$ & --- & --- & --- & --- & --- & --- & --- \\
\hline R01-4 & -- & --- & --- & --- & --- & --- & --- & $\mathrm{V}^{-} \mathrm{O}^{-}$ & --- & --- & --- \\
\hline R14-1 & --- & --- & --- & $\mathrm{B}^{+} \mathrm{N}^{+}$ & --- & --- & --- & --- & --- & --- & --- \\
\hline R14-2 & --- & --- & --- & $\mathrm{B}^{+} \mathrm{N}^{+}$ & --- & --- & --- & --- & $-\cdots$ & --- & --- \\
\hline R14-3 & --- & $-\cdots$ & --- & $\mathrm{N}^{+}$ & -- & --- & --- & --- & --- & --- & --- \\
\hline T19-1 & --- & --- & --- & --- & --- & --- & --- & --- & $\mathrm{O}^{+} \mathrm{T}^{+} \mathrm{B}^{+}$ & --- & --- \\
\hline S04-1 & --- & --- & --- & $\mathrm{V}^{-} \mathrm{O}^{-} \mathrm{T}^{-} \mathrm{B}^{-}$ & --- & --- & --- & --- & --- & --- & --- \\
\hline S04-2 & --- & --- & --- & $\mathrm{N}^{+}$ & --. & --- & --- & --- & --- & --- & --- \\
\hline S04-3 & --- & --- & --- & --- & --- & $\mathrm{B}^{+}$ & --- & --- & --- & --- & --- \\
\hline S04-4 & --- & --- & --- & --- & --- & --. & $\mathrm{N}^{+}$ & --- & --- & --- & --- \\
\hline M08-1 & --- & --- & --- & --- & --- & $\mathrm{B}^{+}$ & --- & --- & --- & --- & $\cdots$ \\
\hline M08-2 & --- & --- & --- & $\mathrm{N}^{+}$ & --- & --- & --- & --- & --- & -- & --- \\
\hline
\end{tabular}

Triticeae polyploids [16]. In this particular case, the clustering pattern shown by the tree is, once again, consistent with previous evolutionary information. Although Ae. ovata and Ae. biuncialis cluster together according to their genomic constitution (both are UUMM), both species are clearly separated in the dendrogram. This suggests that despite the latest genome nomenclature for the Aegilops group [15, 26], superindex should be used to differentiate the $\mathrm{M}$ genomes of both species. This has been proposed in the past by Kihara [11].

A recent study based on molecular markers [1] has demonstrated the phylogenetic proximity of the $\mathrm{N}$ and $\mathrm{U}$ genomes of Ae. uniaristata $(\mathrm{NN})$ and $A e$. umbellulata (UU). This finding was confirmed in the present study in which these species appear as the most closely related diploids. Ae. caudata (CC) and Ae. commosa (MM) share similar morphologi- 
cal features despite their different genomes. The proximity observed between the $\mathrm{C}$ and $\mathrm{M}$ genomes is consistent with this phenotypical similarity [14]. The difference between the genomes $\mathrm{M}$ and $\mathrm{N}$ of Ae. commosa and Ae. uniaristata is also supported by the present findings. In the past, $\mathrm{N}$ was regarded as a modification of $M$ [11] although recent data suggest that it is a different genome $[1,13]$.

Population 434 of Ae. biuncialis was dissociated from the other Ae. biuncialis populations and clustered with the Ae. neglecta group. Ae. biuncialis and Ae. neglecta share the $\mathrm{U}$ and $\mathrm{M}$ genomes. Although mainly self-fertilising, some degree of allogamous behaviour has been described and artificial hybrids have been obtained between species [16]. The natural formation of hybrids by polyploids which share genomes and habitats has been described as a common process [8]. A similar process might explain the segregation shown by population 434 .

\subsection{Correlation between RAPD variability and environmental factors}

Dawson et al. [4] reported some of the RAPD diversity detected in the Triticeae species to be associated with ecogeographical factors. In the present study, some significant correlations $(P=0.01)$ were found between 29 amplified bands and eight bioclimatic and ecogeographical variables (table $I V$ ). This suggests adaptative variation at certain loci. Variables associated with rainfall were those most frequently correlated. Fifteen markers were correlated with mean annual rainfall (Panu), one with summer rainfall, six with altitude (one of which showed simultaneous correlation with Panu), two with longitude, two with latitude, and the remaining four with thermal variables. Ae. neglecta is found in the western half of the Iberian peninsula which has higher rainfall. Fifteen bands corresponding to this species were positively correlated with annual rainfall, which reflects the ecogeographical conditions in which the populations are found. Further, the markers S04-1 and S04-2 generated by the S04 primer were negatively and positively correlated with Panu, respectively. S04-1 (about $900 \mathrm{bp}$ ) appeared in all the species but $A e$. neglecta, while S04-2 (about $850 \mathrm{bp}$ ) was only present in Ae. neglecta. This suggests that both bands correspond to allelic forms of a gene involved in the adaptation to water conditions. At a significance level of $P=0.05$ (data not shown), the correlations scored showed 17 involving Ae. ventricosa bands which simultaneously and negatively affected the mean annual temperature, the mean maximum temperature of the coldest month and the Mediterranean index, all of which is consistent with the distribution pattern of this species. Ae. ventricosa mainly colonises the colder highlands of the Iberian peninsula which suggests that these bands are possible molecular markers of cold adaptation. The negative correlation with the Mediterranean index is consistent with the distribution of the species restricted to the mountains of the Mediterranean region. Future work on Aegilops within the current plant breeding programme will include the isolation and cloning of the markers of most interest.

Acknowledgements: The authors thank the INIA (Instituto Nacional de Investigación y Técnología Agraria y alimentaria del M.A.P.A.) and the GICYT (Dirección general de Investigación Científica y Técnica del M.E.C.) for the financial support of this work (project SC93-176-C2).

\section{References}

[1] Badaena E.D., Friebe B., Gill B.S., Genome differentiation in Aegilops 2. Physical mapping of $5 \mathrm{~S}$ and $18 \mathrm{~S}-26 \mathrm{~S}$ ribosomal RNA gene families in diploid species, Genome 39 (1996) 1150-1158.

[2] Cadwell K.A., Kasarda D.D., Assessment of genomic and species relationships in Triticum and Aegilops by PAGE and by differential staining of seed albumins and globulins, Theor. Appl. Genet. 52 (1978) $273-280$.

[3] Clark A.G., Lanigan C.M.S., Prospects for estimating nucleotide divergence with RAPDs, Mol. Biol. Evol. 10 (5) (1993) 1096-1111.

[4] Damania A.B., Biodiversity and Wheat Improvement, John Wiley \& Sons, ICARDA, 1993.

[5] Dawson I.K., Chalmers K.J., Waugh R., Powell W., Detection and analysis of genetic variation in 
Hordeum spontaneum populations from Israel using RAPD markers, Mol. Ecol. 2 (1993) 151-159.

[6] Dellaporta S.L., Wood J., Hicks J.B., A plant DNA minipreparation: version II, Plant Mol. Biol. Rep. 1 (1983) 19-21.

[7] Devos K.M., Gale M.D., The use of random amplified polymorphic DNA markers in wheat, Theor. Appl. Genet. 84 (1992) 567-572.

[8] Feldman M., Evolutionary studies in the Aegilops-Triticum group with special emphasis on causes of variability in the poliploids species of section Pleionothera, Ph. D. thesis, The Hebrew University of Jerusalem, Israel, 1963.

[9] Gupta P.K., Baum B.R., Nomenclature and related taxonomic issues in wheats, triticales and some of their wild relatives, Taxon 35 (1986) 144-149.

[10] Hawkes J.G., Crop genetic resources, Field collection manual for seed crops, root and tuber crops, tree fruit crops and related wild species, IBPGR, Eucarpia, Rome, 1980.

[11] Kihara H., Tanaka M., Wheat Information Service 30 (1970) 1-2.

[12] Kimber G., Alonso L.C., The analysis of meiosis in hybrids. III. Tetraploid hybrids, Can. J. Genet. Cytol. 23 (1981) 235-254.

[13] Kimber G., Sears E.R., Assignment of genome symbols in the Triticeae, Proc. 6th Int. Wheat Genet Symp, Kyoto, Japan, 1983.

[14] Kimber G., Feldman M., Wild wheats, An introdution, Special Report 353, University of Missouri, USA, 1987.

[15] Kimber G., Tsunewaki T., Genome symbols and plasma types in the wheat group, Proc. 7th Int. Wheat Genet. Symp., Cambridge, UK, 1988.

[16] Kimber G., Yen Y., Hybrids involving wheat relatives and autotetraploid Triticum umbellulatum, Genome 32 (1989) 1-5.

[17] Link W., Dixkens C., Singh M., Schwall A., Melchinger M., Genetic diversity in european and mediterranean faba beab germ plasm revealed by RAPD markers, Theor. Appl. Genet. 90 (1995) 27-32.
[18] Nakai Y., Isozyme variation in Aegilops and Triticum. IV, The origin of common wheat revealed from the study of sterase isozymes in synthesized hexaploid wheats, Japan J. Genet. 54 (1979) 175-189.

[19] Nakai Y., Origen and differentiation of Aegilops triuncialis $\mathrm{L}$. as determined by esterase isozyme analysis, Theor. Appl. Genet. 59 (1981) 169-175.

[20] Ruiz-Fernandez J., Casanova C., Soler C., Collecting Spanish populations of the Genus Aegilops L., Genet. Resour. Crop Evol. 42 (1995) 339-345.

[21] Rolhlf J.F., NTSYS.pc: numerical taxonomy and multivariate analysis system for the IBM pc microcomputer (and compatibles), Applied Biostatistics, Inc., Setavek, NY, 1989.

[22] Saiki R.F., Gelfond D.H., Stoffel S., Scharf S.J., Higuchi R., Horn B.T., Mullis K.B., Erlich H.A., Primer directed enzymatic amplification of DNA with a thermostable DNA polymerase, Science 239 (1988) 487-491.

[23] Schnell R.J., Ronning C.M., Knight R.J., Identification of cultivars and validation of genetic relationships in Mangifera indica L. using RAPD markers, Theor. Appl. Genet. 90 (1995) 269-274.

[24] Sneath P.H.A., Sokal R.R., Numerical Taxonomy, Freeman, San Francisco, 1973.

[25] Thormann C.E., Ferreira M.E., Camargo L.E.A., Comparison of RFLP and RAPD markers to estimating genetic relationships within and among cruciferous species, Theor. Appl. Genet. 88 (1994) 973-980.

[26] Wang R.C.C., Jesen K.B., Jaussi C., Triticeae, 2nd Int. Symp., Logan, Utah, USA, 1994.

[27] West J.C., McIntyre C.L., Appels R., Evolution and systematic relationships in the Triticeae, Pl. Sys. Evol. 160 (1988) 1-28

[28] Williams G.K., Kubelik A.R., Livak K.J., Rafalski J.A., Tingey S.V., DNA polymorphisms amplified by arbitrary primers are useful as genetic markers, Nucleic Acids Res. 18, 22 (1990) 6531-6535.

[29] Yang X., Quiros C., Identification and classification of celery cultivars with RAPD markers, Theor. Appl. Genet. 86 (1993) 205-212. 